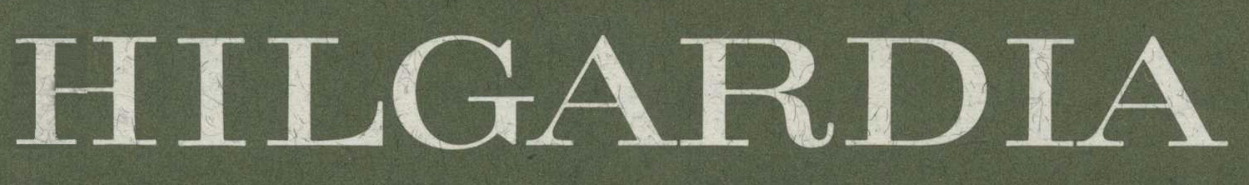

A JOURNAL OF AGRICULTURAL SCIENCE PUBLISHED BY THECALIFORNIA AGRICULTURAL EXPERIMENT STATION

Volume 40, Number $10 \cdot$ December, 1970

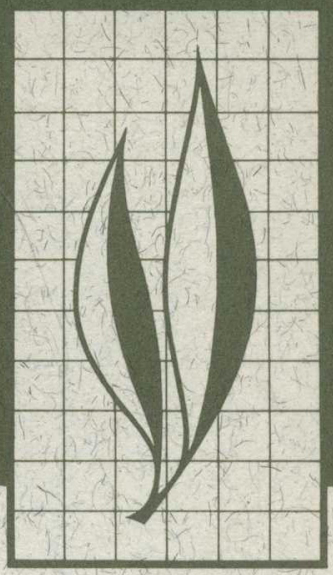

Biological Control of Pacific Mites and Willamette Mites in San Joaquin Valley Vineyards

I. Role of Metaseiulus occidentalis

II. Influence of Dispersion Patterns of Metaseiulus occidentalis

D. L. Flaherty and C. B. Huffaker 


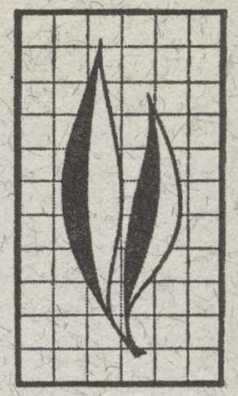

\section{Role of Metaseiulus occidentalis}

Population studies in southern San Joaquin Valley vineyards showed that the distributional patterns of Willamette mite, Eotetranycbus willamettei Ewing, and Pacific mite, Tetranychus pacificus, differ in the Valley, in the vineyard, and on the vine itself. Pacific mite generally does best under hot and dry conditions while Willamette mite prefers cooler and more humid conditions, although there is considerable overlapping of the two species.

Detailed populations studies showed that untreated vineyards with no histories of pesticide treatment often exhibit more efficient levels of predation than do vineyards which have been treated. Also, contrary to the views of some investigators, these studies indicate that Metaseiulus occidentalis (Nesbitt) has no self-limiting aspects in its response to low or high prey densities.

In undisturbed vineyards, a mild predator-prey interaction appears to help perpetuate effective control of low prey densities by $M$. occidentalis. In disturbed vineyards, widely fluctuating predator and prey populations may lead to population crashes and continuation of imbalance. Moreover, when regulating low, but potentially serious, Pacific mite densities in undisturbed vineyards, $M$. occidentalis appears to benefit from the presence of the less seasonally restricted Willamette mite.

Tonnage and fruit-quality data showed that Willamette mite is often not a significant pest. Little differentiation has been made in the past between Pacific mite and Willamette mite, and treatments have been applied as if both were serious pests.

continued inside back cover

\section{THE AUTHORS:}

D. L. Flaherty is Assistant Research Entomologist in the Experiment Station, Berkeley.

C. B. Huffaker is Professor of Entomology and Entomologist in the Experiment Station, Berkeley. 


\section{Influence of Dispersion Patterns of Metaseiulus occidentalis}

\section{INTRODUCTION}

THE SENIOR AUTHOR has been engaged in an effort to develop programs of integrated control for spider mites and associated pests of commercial grapes in the San Joaquin Valley for several years. As discussed by Huffaker and Flaherty (1966) and Flaherty and Huffaker (part I), spider mites (Acarina: Tetranychidae), constitute a major problem in the development of such programs. Two species, the Pacific mite, Tetranychus pacificus McGregor, and Willamette mite, Eotetranychus willamettei Ewing, commonly occur in San Joaquin Valley vineyards. Treatments to control the grape leafhopper, Erythroneura elegantula Osborn, have greatly magnified the spider mite problem.

The above authors present substantial evidence in the work cited above that a predatory mite, Metaseiulus occidentalis (Nesbitt), may provide adequate control for both spider mite species under certain conditions where it is favored by a minimal pesticide program. Their data indicate, in fact, that treatments for control of Willamette mite are not only largely unnecessary, but such treatments may aggravate $\mathrm{Pa}$ cific mite problems-either by destroying predator populations or by eliminating Willamette mite as an alternate prey. The destruction of Willamette mites as alternate prey appears to affect the efficiency of those predators that may not have been killed directly. The predators then have too little food available to survive sufficiently well distributed throughout a vineyard to maintain a satisfactory level of control of the serious species, the Pacific mite.

If extensive effort is to be made toward commercial employment of a given natural enemy in a biological or integrated control program, it must first be shown that the enemy has the potential capacity to serve as a reliable control factor to prevent high densities from developing and suppress them if they do. Among the natural enemies of spider mites in San Joaquin Valley vineyards, the phytoseiid, $M$. occidentalis, in contrast to insectan predators of spider mites, would seem to offer the greatest potential (part I).

This paper deals with the importance of adequate distribution of $M$. occidentalis throughout the vineyard for effective control of spider mites. Much of the divergence of opinion on the role of this predator in San Joaquin Valley vineyards focuses on this factor.

In fact, the divergence of opinion regarding the efficiency of other phytoseiids around the world, as well as $M$. occidentalis here, may result from inadequate attention to predator distribution. Huffaker, van de Vrie, and McMurtry (1969) give a brief synopsis from pertinent literature of certain aspects of this factor and other aspects of phytoseiid efficiency. However, the contentions of Chant $(1959,1961)$ and Kuchlein $(1965,1967)$ were not adequately considered in that review. Chant felt that because of its limited reproductive response, $M$. occidentalis may be unable to control its prey, after densities exceed certain levels. Kuchlein also considered that this species and other phytoseiids as well could act as regulating agents only at low densities of prey. Certain experimental results. referred to by Huffaker, van de Vrie, and McMurtry (1969) are con- 
sistent in some respects with Chant's and Kuchlein's hypothesis of ineffectiveness, while they are also consistent with the contrary hypothesis of effec- tive phytoseiid control of the prey species. This is dealt with in the following section.

\section{THE RELATION OF TOTAL PREDATOR RESPONSE TO PREY DISTRIBUTION IN THE HABITAT}

A good predator need not necessarily frequent or inhabit the areas where the prey occur at all times or at any particular time. But to ascertain true predator efficiency, the authors believe that the dynamic and shifting relationships of population events-densities, dispersion, behavioral and numerical responses, their sequence and timingmust be carefully analyzed from data collected on marked or specific plant units and plant parts under field conditions. Such procedures can lead to conclusions considerably different from those where data have been grossly collected and have received gross statistical treatment.

Chant (1959) and Kuchlein (1965) cast doubt on the ability of phytoseiids in general to control tetranychid populations, although Chant significantly qualified his remarks: "In summation then, I believe that the data presented here indicate that phytoseiids, with the possible exception of Typhlodromus finlandicus, are of little actual or potential value in the control of orchardinhabiting phytophagous mites in southeastern England. This, of course, is not necessarily true of other phytoseiid species in other parts of the world; one fact that emerges from the present study is that each species must be treated individually. Indeed, Huffaker and Kennett (1956) showed that T. reticulatus and T. cucumeris in California have many attributes that are greatly desirable in a predator, and there is little doubt that these species can effectively control the pest Tarsonemus pallidus on strawberry in that part of the world."

Chant further states that when in- verse numerical relationships between predators and prey are obtained as a result of use of chemicals to remove predators as a "check-method," this presents circumstantial evidence of a control action; but it does not establish it. He cited works (p. 37) of many authors that present such circumstantial evidence pertaining to Panonychus $u l m i$ Koch alone. He then cautioned against use of such evidence on the basis of the commonly held view that the chemical used might cause the prey's increase in some other way. Huffaker and Spitzer (1950) were in fact the first to demonstrate a significant mite increase in the absence of any predator influence following use of DDT. Huffaker, van de Vrie, and McMurtry (1969) review this question, and while agreeing that some additional technique as a check on the chemical check-method is essential for clear proof, the abundance of "circumstantial" evidence on a world-wide basis strongly suggests a cause and effect relationship. Chant himself (1961) demonstrated a control effect by Phytoseiulus persimilis Athias-Henriot on Tetranychus urticae Koch in a greenhouse.

Chant (1959) based his conclusion that Typhlodromus pyri Scheuten does not adequately control Panonychus $u l m i$ on apples in England on his studies of its habitat occurrence relative to that of Panonychus ulmi, and on its lack of dependence on $P$. ulmi as food. $\mathrm{He}$ also questioned (1961) the ability of Metaseiulus occidentalis to respond sufficiently as a density-dependent control factor once densities of the prey exceed the level at which its oviposition rate levels off-that is, "unless the im- 
mature predators that hatched from the eggs could mature and start to reproduce at a rate faster than the prey." Laing and Huffaker (1969) found from use of a hypothetical model that this species (also Phytoseiulus persimilis Athias-Henriot) can counteract a leveling off in their functional-attack response or egg-deposition response and still control the prey species. This occurs through the advantage gained in numerical response over a number of successive generations, even though the response within a single generation is limited, as Chant states. The results generated by the model were also comparable to actual population interactions.

Kuchlein (1967) presented data to show that $M$. occidentalis (referred to by Kuchlein as T. longipilus) did not respond and was unable to maintain itself in a greenhouse on bean plants on which very high densities of Tetranychus urticae were maintained by artificial additions. This seems to be a most unusual performance. Kuchlein (1966) also illustrated a form of mutual disturbance among the predators under unusual conditions, but he did not show that this would preclude effective control. Kuchlein (1965) considered that phytoseiids would be able to regulate the numbers of their prey only in a range of the lowest prey densities, if at all. He based this conclusion on his studies of the functional response and his view that they do not exhibit a real, delayed numerical response. (See Huffaker, van de Vrie, and McMurtry, 1969.)

In both field and laboratory, $M$. occidentalis has exhibited a striking ability to thrive among very dense colonies of several species of spider mites and to suppress them with ease. If the sequence of events in Huffaker's (1958) and Huffaker's et al. (1963) experiments are followed, it is abundantly clear that this predator readily reduced high, intermediate, or low densities.
Similar results were found by Laing (personal communication) in his plantby-plant studies of predation by this species on $T$. urticae on strawberry plants and by Huffaker and Kennett in their unpublished 1951 to 1956 data from plant-by-plant studies of predation by two other phytoseiids of cyclamen mites on field strawberries. Huffaker, van de Vrie, and McMurtry (1969) cite examples wherein several species of phytoseiids were reported to thrive among and to suppress high densities of various prey species.

Chant's (1959) study of phytoseiid predation in English apple orchards was in many respects thorough, and his basic conclusions regarding Typhlodromus pyri cannot be taken lightly. He considered T. pyri of "little actual or potential value." (For a contrary view and aspects of the question not considered here, the reader is referred to Dosse, 1960; Collyer, 1964a, $b$; van de Vrie and Kropczyńska, 1965; Kropczyńska and van de Vrie, 1965; Huffaker, van de Vrie and McMurtry, 1969.)

For one point, Chant (1959) correctly considered that an effective predator must exhibit a concurrence in habit with that of its prey. He made good use of this approach relative to the way in which T. pyri and $P$. ulmi inhabit the leaves, but his use of leaf-frequency distribution patterns is open to criticism. He showed that on field trees $T$. pyri was confined mostly to the lower leaf surface midribs, and since they do not particularly need to rely on $P$. ulmi for food they may not leave those haunts to prey on the $P$. ulmi elsewhere. The prey species was well distributed over the whole leaf, both upper and lower surfaces. He then commented, "Phytoseiids occur on all parts of the leaves on apple seedlings, probably because of the peculiar character of seedling leaves, and this may account for the success of predation on seedlings in the face of contradictory field evidence." 
Differences in dispersion patterns of predators and prey over the plant parts at given times have been noted by a number of other workers to account for a lagging predator response and ineffectiveness at the time (Anderson and Morgan, 1958; Flaherty 1969; Flaherty and Huffaker, part I; Huffaker, 1958; Huffaker, Shea, and Herman, 1963).

The other approach (Chant, 1959; Chant and Fleschner, 1960) to the problem of evaluating the dispersion factor, that is, the plotting of leaf-infestation frequency distributions of predator and prey populations, is misleading. The predator-prey interactions occurring over a period of time directly alter these relations. While it may be possible to show that the predator- and preyfrequency distributions vary greatly in one manner at a given time, then in an opposite way at a later time and correspond somewhat better at some intermediate time-this does not provide any evidence of a controlling relationship on the part of the predator. Moreover, Kropczyńska and van de Vrie (1965) utilized an alternative "correlation diagrams" approach which seems subject to the same criticism. With neither method do we gain insight as to what is happening on specific plant parts, for these are not tabbed and followed individually over a period of time to observe the changes.

We agree with Kropszyńska and van de Vrie's (1965) pertinent statement, that if the predator is efficient, the two species will not reach peak densities simultaneously on the same leaf, for the two peaks occur at quite different times. The same is true for their minimums. The peak in predator density, and its maximum dispersion occurs well after the peak density and maximum dispersion of the prey. At one time there are one or a very few predators and moderate numbers of prey, followed by high numbers of prey and a few predators; and then as high numbers of predators are attained, the prey have been reduced to moderate or low numbers.

Kropszyńska and van de Vrie (1965) go on to state that the predatory mites, as indicated in the authors' correlation diagrams, occur almost entirely on leaves having only low to moderate densities of the prey. They add that this establishes a dependency, and that "This can only be explained by assuming that the predators have a diminishing effect on the prey." This, to be sure, shows that the predators are not distributed independently of the prey; and it is consistent with the views expressed by the authors, but it does not prove them. Nor does it disprove the contrary view of Kuchlein (1965): that such predators are effective only at low prey densities, if at all. Kropszyńska and van de Vrie's (1965) results are, in fact, consistent with Kuchlein's (1965) view, too, but they do not prove it.

The data from glasshouse studies presented by Kropczyńska and van de Vrie (1965) do not tell us what happened on specific leaves. Looking at figures 1 and 2 of their paper, decline for the prey population concerned began after July 9 and reached a fairly low level by July 16 . This decline from a high density occurred before adequate numbers of predators were present to account for it. The control, having no predators present, follows a similar pattern. The predator increase, occurring only after considerable prey decline, suggests a consistency with Kuchlein's hypothesis that phytoseiids are responsive to and can control low prey densities but not high densities. In another paper, however, reporting on field rather than laboratory studies, van de Vrie and Kropszyńska's (1965) data strongly suggest that when Typhlodromus potentillae Garmen is well distributed on apple trees, it can effectively respond to and control either high or low densities of Panonychus ulmi.

Other workers-Smith $(1 \dot{9} 39,1950)$; Smith and Stafford (1955); and R. O. 
Schuster (personal communication)who have investigated California grape pests, have placed little value on $M$. occidentalis. Their studies and observations led them to believe it to be ineffective against either Pacific mite or Willamette mite. For instance, R. $O$. Schuster (personal communication), whose studies were conducted in 1964 and 1965 in the Lodi area of the San Joaquin Valley, did not find significant differences in Willamette mite numbers whether this predator was present or absent. He believed that $M$. occidentalis depends upon Willamette mites as food, but it does not control their numbers. Schuster also believed that $M$. occidentalis does not possess the ability to respond numerically to increases of low prey densities, only at high prey densities. It should be noted that this view is contrary to Kuchlein's (1965, 1966, 1967) hypothesis.

Smith and Stafford (1955) emphasized the agility of the Willamette mites which they considered allows escape from predation - demonstrating the supposed inefficiency of the predator. This presumption is curious in view of the fact that $M$. occidentalis favors spider mite eggs as food. Other sedentary stages are also available. Agility in the prey species is probably of little value. Tetranychid mites are commonly indifferent to the approach of predators.

Smith (1939) and Smith and Stafford (1955) state that $M$. occidentalis occasionally holds Pacific mites at low densities, and treatments may not be needed. The latter investigators believed that Pacific mites are less agile than Willamette mites and fewer predation escapes are possible. Flaherty (1969) and Flaherty and Huffaker (part I), however, showed that $M$. occidentalis under favorable conditions is not only effective at very low densities of Pacific mites and two-spotted mites (Tetranychus urticae Koch), but at low densities of Willamette mites as well. Thus, they seem responsive either at low or high prey densities; and under favorable conditions, they prevent high densities from developing or suppress them if they do.

Thus, conflicting opinions exist among investigators not only with regard to the ability of $M$. occidentalis to control either high or low prey densities, but also with regard to its ability to control Willamette mites at any density. But since laboratory workers in California (Waters, 1955; Huffaker, 1958; Huffaker et al., 1963; and more recently, Laing and Huffaker, 1969) clearly showed that the California stock used has no self-limiting aspects that preclude response and control at either high or low densities, it was felt for the present study that predator and prey dispersion or distributional patterns might well disclose why these contrary opinions exist among field investigators. Moreover, such studies might also disclose why this predator in vineyards with pesticide histories often exhibit poor predator responses, despite the presence of high prey densities; while in untreated vineyards, the predator often quickly responds to small increases of prey numbers at low densities (see Flaherty and Huffaker, part I).

\section{STUDIES}

\section{Methods}

Dispersion or distributional patterns of $M$. occidentalis and its prey, Williamette mite and Pacific mite, on grapevines were observed in general studies initiated in 1965. Population counts in the Miguel vineyard near Biola, Fresno County, showed fairly high densities of both Willamette mite and Pacific mite. Thus, for purposes of this investigation, 56 vines on two adjacent rows were left untreated by the grower. The 


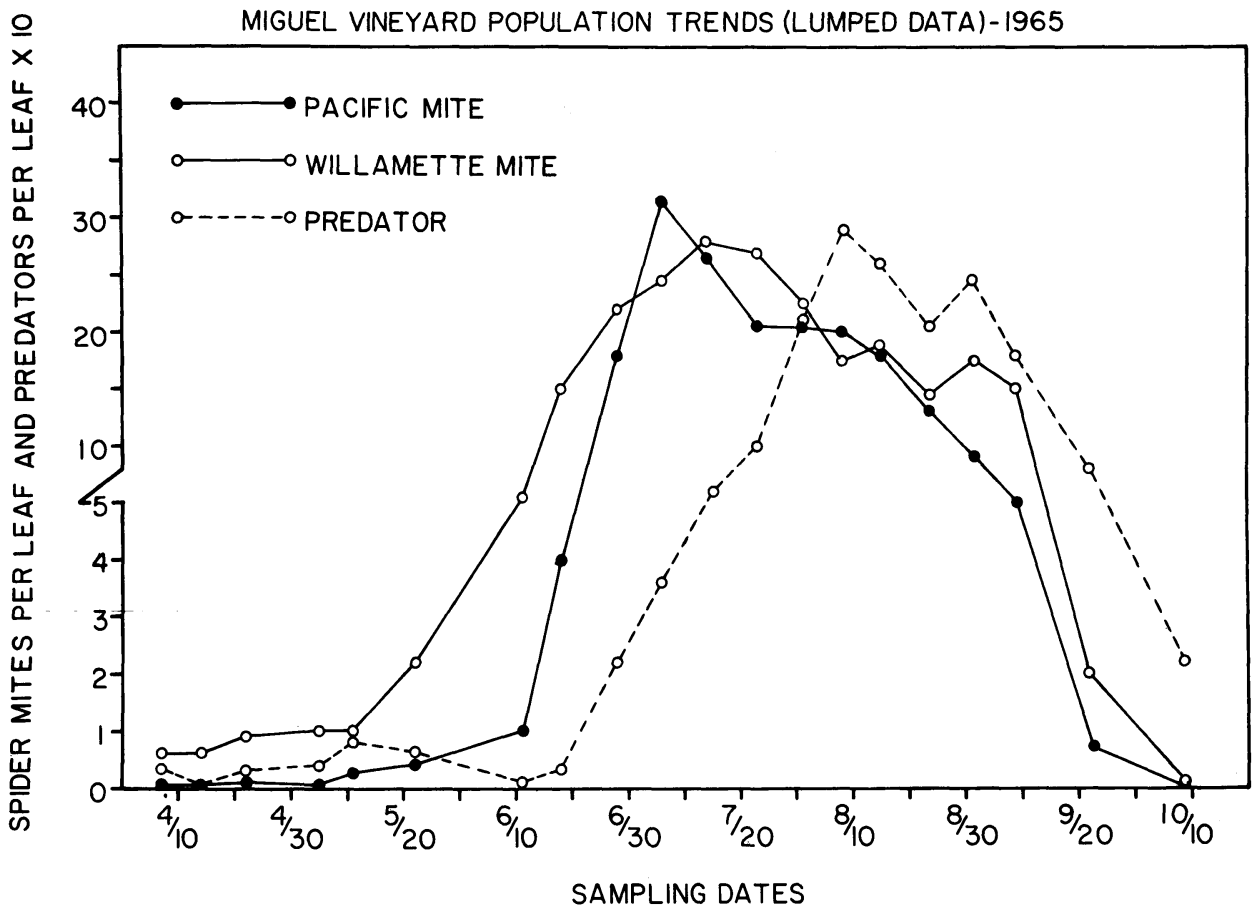

Fig. 1. Population counts for each sampling date lumped from all 56 vines in plot.

rest of the vineyard was treated as usual. This vineyard had had an unbroken history of chemical treatments.

From each of the 56 vines, 20 leaves were taken from the basal section of canes, 20 from the middle sections, and 20 from the distal sections. This scheme of sampling was repeated on the north and south sides and tops of the vines. An attempt was made to choose those leaves which received full afternoon sun on the south side, those receiving no direct afternoon sun on the north side, and those on canes extending upward from the tops of vines. A total of $\mathbf{1 8 0}$ leaves ( 60 from the north side, 60 from the south side, and 60 from the top) were collected on each of 11 sampling dates from July 3 to October 30, 1965.

A stereoscopic microscope was used to make spider mite and predator counts. Spider mite eggs were counted but not included in the 1965 results. All stages of the predator were lumped into single counts. The areas of the leaves were estimated by matching them with sketched leaves of a series of different sizes. Figure 1 illustrates the population trends on the sampled vines. Table 1 summarizes the 1965 distributional data.

\section{Results and discussion}

Table 1 shows that greater numbers of predators occupied the hotter, sunnier areas of the vines favored by Pacific mites. Fewer predators were on the cooler, shadier north sides of the vines-the area favored by greater numbers of Willamette mites. Moreover, the table shows that Willamette mites, in contrast to Paciflc mites, are less selectively distributed over the categorized vine positions.

The table also indicates that the number of predators is influenced by spider mite density, in numbers per leaf or numbers per square inch of leaf surface. This is clear when one considers the slight difference in absolute num- 
TABLe 1

INTRA-VINE DISTRIBUTIONAL PATTERNS OF THE PREDATORY MITE METASEIULUS OCCIDENTALIS (NESBITT) WITH RESPECT TO ITS PREY, EOTETRANYCHUS WILLAMETTEI EWING AND TETRANYCHUS PACIFICUS MCGREGOR, ON THOMPSON SEEDLESS GRAPEVINES IN THE MIGUEL

VINEYARD

(BIOLA, FRESNO COUNTY, 1965)

\begin{tabular}{|c|c|c|c|}
\hline \multirow{2}{*}{ Item } & \multicolumn{3}{|c|}{ Area on vine } \\
\hline & North & South & Top \\
\hline No. leaves sampled (11 sixty-leaf samples)............ & 660 & 660 & 660 \\
\hline 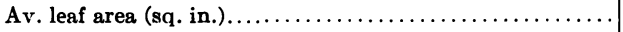 & 19 & 16 & 11 \\
\hline Total area sampled (sq. in.) $\ldots \ldots \ldots \ldots \ldots \ldots \ldots \ldots \ldots$ & 12,540 & 10,560 & 7,260 \\
\hline 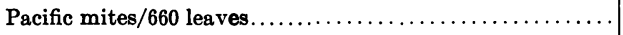 & 3,714 & 8,902 & 10,732 \\
\hline Willamette mites $/ 660$ leaves. . . . . . . . . . . . . . . . & 11,391 & 8,740 & 6,071 \\
\hline 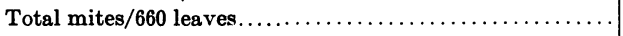 & 15,105 & 17,642 & 16,803 \\
\hline 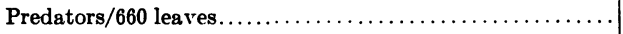 & 754 & 1.182 & 1,259 \\
\hline Pacific mites/leaf........... & 5.7 & 13.5 & 16.3 \\
\hline Willamette mites/leaf $\ldots \ldots \ldots \ldots \ldots \ldots \ldots \ldots \ldots \ldots \ldots$ & 17.2 & 13.2 & 9.2 \\
\hline 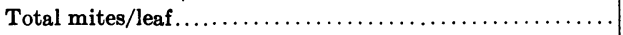 & 22.9 & 26.7 & 25.4 \\
\hline 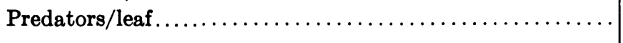 & 1.1 & 1.8 & 1.9 \\
\hline Pacific mites/sq. in. $\times 10 \ldots \ldots \ldots \ldots \ldots \ldots \ldots \ldots \ldots \ldots \ldots \ldots \ldots \ldots \ldots \ldots$ & 3.0 & 8.4 & 14.8 \\
\hline Willamette mites/sq. in. $\times 10 \ldots \ldots \ldots \ldots \ldots \ldots \ldots \ldots$ & 9.1 & 8.3 & 8.4 \\
\hline Total mites/sq. in. $\times 10 \ldots \ldots \ldots \ldots \ldots \ldots \ldots \ldots \ldots \ldots \ldots$ & 12.1 & 16.7 & 23.1 \\
\hline \multirow[t]{3}{*}{ 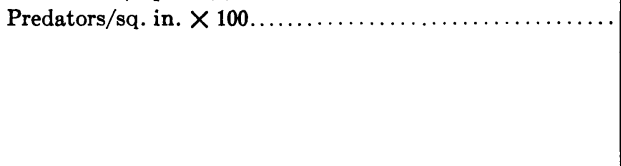 } & 0.6 & 1.1 & 1.7 \\
\hline & \multicolumn{3}{|c|}{ Significance level (from paired $t$-test)* } \\
\hline & Top vs North & Top vs South & South vs North \\
\hline Pacific mites $/ 660$ leaves..$\ldots \ldots \ldots \ldots \ldots \ldots \ldots \ldots \ldots$ & .05 & NS & .05 \\
\hline Willamette mites $/ 660$ leaves. $\ldots \ldots \ldots \ldots \ldots \ldots \ldots \ldots$ & NS & NS & NS \\
\hline 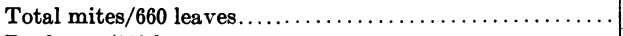 & NS & NS & NS \\
\hline 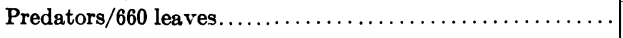 & .05 & NS & NS \\
\hline Pacific mites/leaf........ & .05 & NS & .05 \\
\hline Willamette mites/leaf $\ldots \ldots \ldots \ldots \ldots \ldots \ldots \ldots \ldots \ldots$ & NS & NS & NS \\
\hline Total mites/leaf $\ldots \ldots \ldots \ldots \ldots \ldots \ldots \ldots \ldots \ldots \ldots \ldots \ldots \ldots \ldots \ldots \ldots \ldots$ & NS & NS & NS \\
\hline 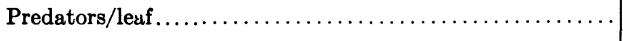 & .05 & NS & NS \\
\hline Pacific mites/sq. in. $\times 10 \ldots \ldots \ldots \ldots \ldots \ldots \ldots \ldots \ldots \ldots \ldots \ldots \ldots \ldots \ldots \ldots$ & .05 & .05 & .05 \\
\hline Willamette mites/sq. in. $\times 10 \ldots \ldots \ldots \ldots \ldots \ldots \ldots \ldots$ & NS & NS & NS \\
\hline Total mites/sq. in. $\times 10 \ldots \ldots \ldots \ldots \ldots \ldots \ldots \ldots \ldots \ldots \ldots \ldots \ldots \ldots \ldots \ldots$ & .05 & .05 & NS \\
\hline 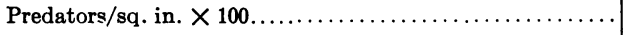 & .05 & .05 & NS \\
\hline
\end{tabular}

$* \mathrm{NS}=$ not significant at $5 \%$ level.

bers of the two prey species combined, contrasting the three vine positions; this number varied from 15,105 to 17,642. However, a considerable difference occurred in numbers per square inch, varying from 12.1 to 23.1. Thus, the slower response of predator populations to Willamette mites could be, at least in part, a function of the prey population dispersion. The concentration of food represented by the Pacific mites, not only in numbers but also in food bulk per mite (all stages of the Pacific mite are larger than those of the Willamette mite) would certainly favor the predator, whereas the greater dispersion of Willamette mites might not favor the predator-even if the two species were equal in numbers. The numerical response to a more dispersed prey population would be slower and perhaps less effective. On the other 
hand, once a predator finds the Pacific mite, which commonly occurs in aggregations, it destroys more mites than it does in the initial encounter with the Willamette mite-which does not commonly occur in aggregations. It seems self-evident that less energy would be used in searching and more used in reproduction. Furthermore, the webbing presented by Pacific mite infestation in these aggregates would also be advantageous in predator response. Willamette mites produce less webbing than do Pacific mites on grape foliage. Flaherty (1969) considered that small aggregations of two-spotted mites, a Tetranychus species related to the $\mathrm{Pa}$ cific mite which webs profusely on grape leaves, improved predation over that resulting on the more dispersed Willamette mites. Also, C. E. Kennett and J. A. McMurtry (personal communications) concluded that $M$. occidentalis prefers to feed in tightlywebbed colonies.

Further, table 1 suggests that prey population density has more influence on predator action, than do individual prey attributes (such as agility), although we still have not shown prey agility to be entirely unimportant. Con- trasting the north and south sides of the vines, no significant difference occurred in numbers of predators or total spider mites (both species) per square inch, although there was a significant difference in Pacific mites per square inch. Thus, if the Pacific mite is inherently favored over the Willamette mite, significantly more predators should occur per square inch on the south sides of the vines, but this was not the case. Furthermore, significantly more predators per square inch occurred on the tops of vines and the top leaves than in the other two positions, which were not statistically different themselves. This correlates well with the fact that significantly more total prey per square inch occurred on the top leaves than in the other two positions, which again, themselves, were not statistically different.

Thus, these data indicate that if this predator is more efficient against the Pacific mite than it is against the Willamette mite, as has been suggested, it is because the former presents a greater concentration of food for the predator, not necessarily because of any inherent acceptability or lack of agility of the prey.

\section{STUDIES}

\section{Methods}

In the general study made in 1965 , vines appeared to harbor high populations of Willamette mites and low populations of Pacific mites, and vice versa. Also, while populations on some vines were increasing, others were decreasing. Predation and vine injury seemed responsible for such variation in phases of the populations. Obviously, pooling of data from vines of a group presenting such phase differences would preclude the most critical data. Huffaker and Kennett (unpublished data, 1952 to 1956), using small groups of strawberry plants as study units, found that the fortunes of populations of the cylamen mite, Stenotarsonemus pallidus (Banks), were a function of distributional patterns of the predators Amblyseius aurescens Athias-Henriot and $\boldsymbol{A}$. cucumeris (Oudemans). This critical information was obscured when data were lumped from samples taken from plants scattered over a sizeable area. Very small units of the plant habitat were then taken as the sampling basis for lumping of data ( 30 plants). Therefore, to better understand the corresponding interrelations of the three species on grapevines in this study, vines were sampled individually in 1966 , and the population changes on 
each separate vine were followed throughout the season.

So that populations would not be disturbed by removing too many leaves from a vine being sampled, a minimum of three leaves (basal, middle, and distal cane leaves) were taken from the north, south and top positions of each vine. Thus, nine leaves were taken from each vine on each sampling date. Figure 2 presents the plot design.

Initially, 24 vines in rows 59 to 62 were sampled; later, six more vines from row 58 were included. The vines in row 58 afforded a better opportunity to compare results, for observations indicated that predators were active earlier on these vines than on the original 24 vines. Six vines on row 57 were picked up after the grower treated the vineyard, including this row, with dicofol. Therefore, an opportunity was at hand to illustrate what occurs on individual vines after such treatments. The pre-treatment counts on row 57 were assumed to have been the same as those on row 58 . Vines in these two rows appeared to have similar early-season predator and prey activity. Rows 57, 58,61 , and 62 were treated in 1965 ; rows 59 and 60 were not.

Figure 3 illustrates six representative population trends out of the 36 vines. Figures 4 to 9 illustrate the population trends on the 36 individual vines, by their respective row. Figure 3 has a slightly different scale than figures 4 to 9 . Table 2 presents percentage of leaves carrying predators and prey during early, middle, and late summer on vines represented by $A, B, C$, and $D$ trends in figure 3 . In table 2 , the data in the A group are lumped from three plot vines, the B group from five vines, the $\mathrm{C}$ group from eight vines, and the D group from five vines. Figure 10 presents how the population trends in 1966 appear when counts from a large number of vines are lumped.

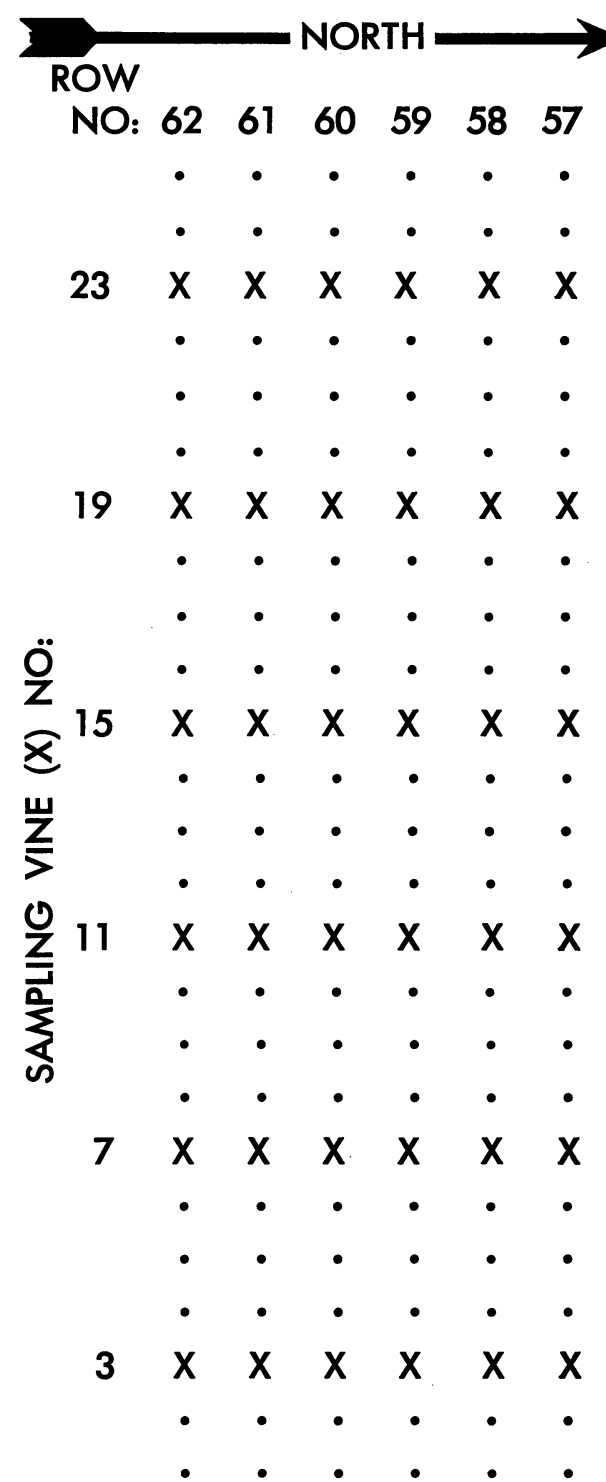

1965* T NT NT T T T $1966 \dagger$ NT NT NT NT NT T ( $\mathrm{T}$ = TREATED; NT = NOT TREATED)

* Treatment: endosulfan and dicofol

$\dagger$ Treatment: dicofol

Fig. 2. Design for Thompson Seedless grapevine plot used to study the distributional patterns of the predator Metaseiulus occidentalis (Nesbitt) and its prey, Eotetranychus willamettei Ewing and Tetranychus pacificus McGregor, in the Miguel vineyard, Biola, Fresno County (1966). 

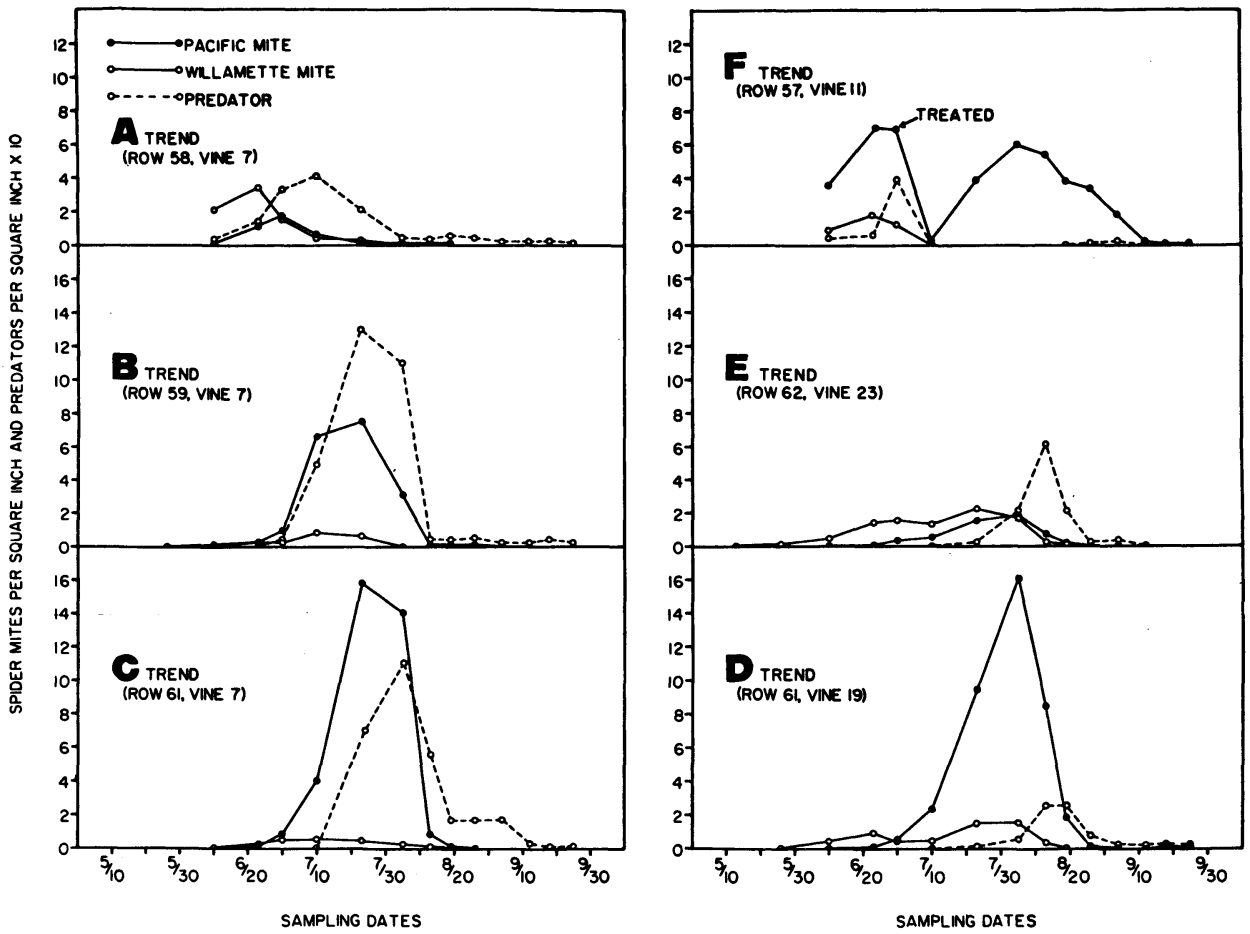

Fig. 3. Population trends on six vines considered representative of 36 sampled. Miguel vineyard, 1966.

\section{Results and discussion}

Unfortunately, results left something to be desired. Pacific mite populations were excessively high, while Willamette mite populations developed rather poorly in comparison (fig. 10). However, the data show that individual vine sampling affords more meaningful results in the study of predator-prey relationships in vineyards than does the lumping of data (fig. 10). Also, the trends observed in 1965, that is, the increasing and decreasing populations correlated with vine injury and occurrence of predators, are confirmed in these 1966 results from individual vine records. Even the intra-vine and intervine variations in Willamette mite and Pacific mite populations are shown, even though the latter species was dominant. However, no difference in predations between Willamette mite and $\mathrm{Pa}$ - cific mite on the vines was shown because of this dominance.

The six populations trends (A through F) in figure 3 show, even in a limited area of such a vineyard, that variation in predator effectiveness can be very great, vine to vine, and that lumped data may present an entirely different picture of predator effectiveness. For example, from the lumped data in figure 10 , one might conclude that $M$. occidentalis is ineffective because its overall response is slow and its action seemingly intensified only at the higher prey densities. However, figure $3 \mathrm{~A}$ (representative of the $\mathbf{1 9 6 6}$ single-vine data) indicates that this predator does not lack ability to respond quickly and effectively even at low prey densities.

Figure 3A represents vines having good numbers of predators during early summer. When this condition prevailed 
TABLE 2

PERCENTAGE OF LEAVES CARRYING PREDATORS AND PREY ON VINES REPRESENTED BY A, B, C, AND D TRENDS IN FIGURE 3 DURING THREE PERIODS OF SUMMER. 1966

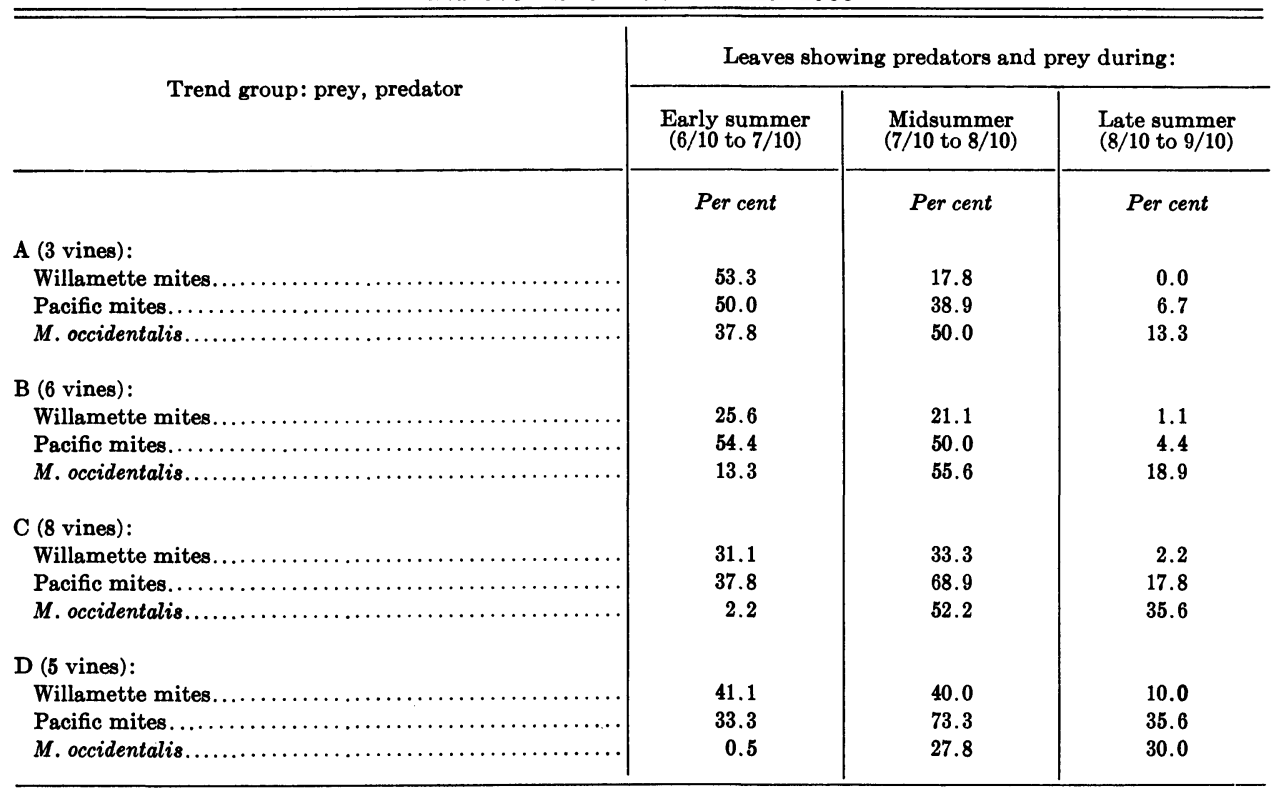

on specific vines, predator response was similiar to that in figure $3 \mathrm{~A}$, plotted in figure 5 from vine 7 in row 58. One other vine (vine 15 , row 58, fig. 5) was comparable, as was its subsequent history. Vine 3, row 58 (fig. 5) was close to comparable, as was its subsequent predator-prey history.

Table 2 shows that trend A vines had predators better distributed with respect to their prey during the early summer period than did B, C, and D vines. Because of better distribution, trend $\mathbf{A}$ vines were considered to have much lower Pacific mite populations during the critical mid-summer period. Note also that the three trend $A$ vines (vines 3,7 , and 15; fig. 5 ) themselves indicate that Pacific mite densities are a function of predator distribution: that is, vine 15 (with lowest seasonal density of Pacific mite) had 46.7 per cent of the leaves with predators during the early-summer period; vine 3 (with the highest Pacific mite density among the three $\mathbf{A}$ vines) had 32.2 per cent of the leaves with predators; and vine 7 (intermediate in Pacific mite density) had 35.6 per cent of the leaves with predators during the earlysummer period.

As a result of early-summer predator activity, all three vines carried more leaves with predators than with Pacific mites during the critical midsummer period (July 10 to August 10); e.g., vine 3 averaged 60 per cent of the leaves with Pacific mites and 62.2 per cent with predators; vine 7 averaged 32.2 per cent of the leaves with Pacific mites and 45.6 per cent with predators; and vine 15 averaged 24.4 per cent with Pacific mites and 43.3 per cent with predators. Pacific mite distribution on these vines during the mid-summer period, like its density, appears to be a function of early-summer predator distribution.

Thus, the predators on the three trend A vines were sufficiently abun- 
ROW 57
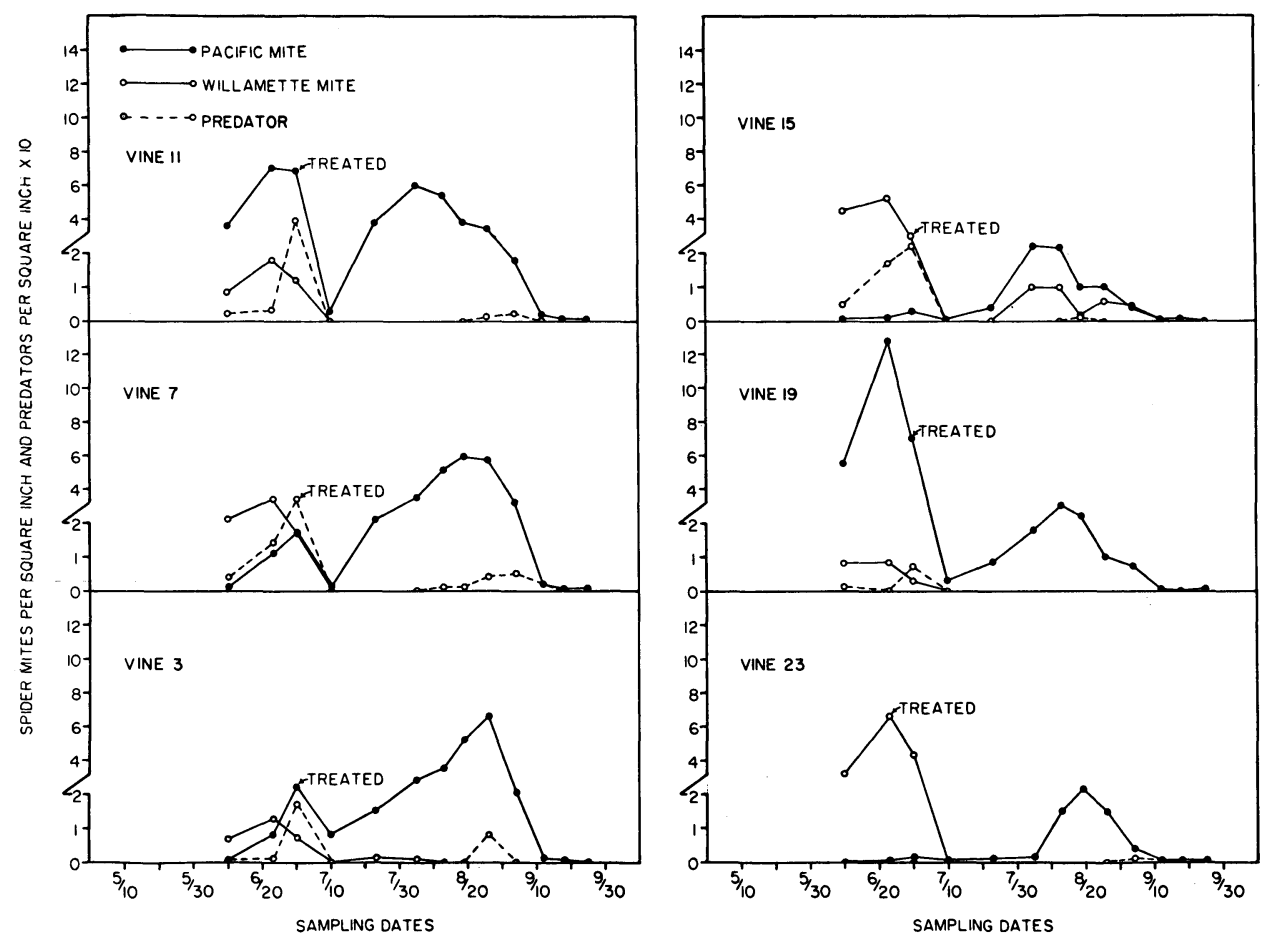

Fig. 4. Population counts on each sample vine. Row 57 was treated with endosulfan and dicofol in 1965 and with dicofol only in 1966. Miguel vineyard, 1966.

dant and adequately distributed to maintain excellent control of Pacific mites during a highly favorable period of increase. The predators did not simply tail the prey populations, exercising little or no control at the critical time. While populations on other vines in the plots were increasing (see below) or peaking in numbers, the predator was severely reducing both species of prey mites on these three vines.

Trend B, figure 3 , represents a good proportion of the vines in the Miguel vineyard plot in 1966, wherein temporary escape from effective predation occurred, because too few predators were present during the critical earlysummer period. Predators were conspicuously lagging in response during the early summer on these vines. The result was temporary escape leading to abundance by Pacific mites. The lag pe- riod on the trend $\mathrm{B}$ vines, however, was relatively short, and the Pacific mite decline was probably due primarily to predation. To some degree, decline was also due to leaf injury caused by its own feeding. The decline was not, however, predominantly seasonal in nature, for a population of comparable numbers (trend F, fig. 3) continued for another month, with a gradual decline. Other vines presenting similar patterns (with slightly more or less lagging responses) were vines 3,11 , and 15 of row 59 (fig. 6 ) and vines 7 and 11 of row 60 (fig. 7 ).

Table 2 shows that predators on trend $B$ vines were less active during the early-summer period than those on trend A vines; for example, trend A vines averaged 37.8 per cent of the leaves with predators during this period, while trend $B$ vines averaged only 
ROW 58
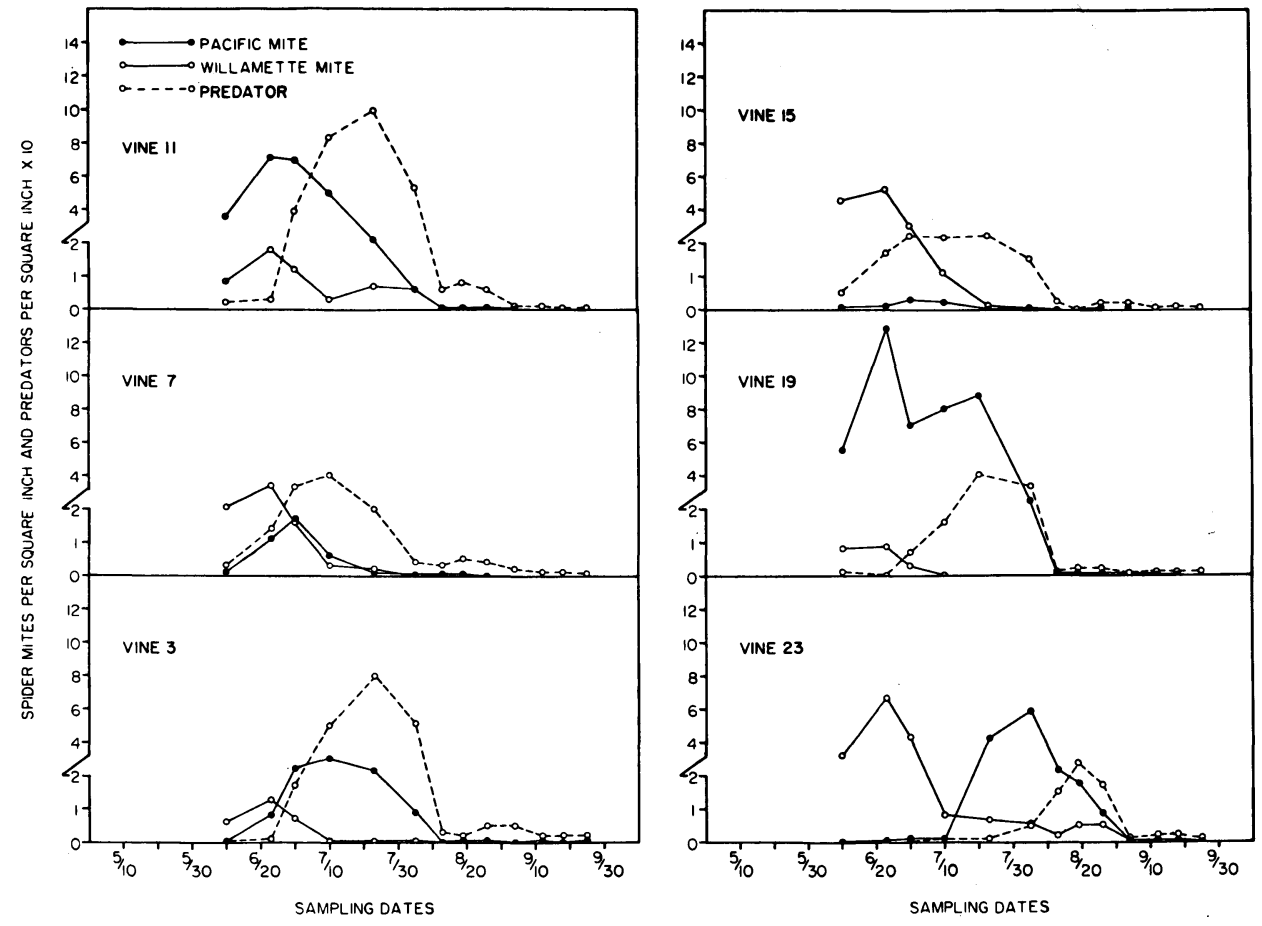

Fig. 5. Population counts on each sample vine. Row 58 was treated with endosulfan and dicofol in 1965 but was not treated in 1966. Miguel vineyard, 1966.

13.3 per cent. Both $\mathrm{A}$ and $\mathrm{B}$ vines had equivalent predator distribution values during the mid-summer period (A vines, 50.0 per cent; $B$ vines, 55.6 per cent). Thus, the difference in Pacific mite densities (compare trends $\mathbf{A}$ and $B$, fig. 3) could be attributed to better distribution of predators on $A$ vines during the early-summer period.

Trend $\mathrm{C}$ vines present a picture similar to that of trend $\mathrm{B}$ vines, but for an even longer lag period. Table 2 shows that 2.2 per cent of the leaves of $\mathrm{C}$ vines had predators during the early-summer period. The number of predators lies between those represented by $B$ and $D$ vines. Less than 0.5 per cent of $D$-vine leaves had predators during the early-summer period. Important also is that $C$ and $D$ vines show that the predator's failure to respond to high prey densities appears due to its poor distribution pattern-not to some inherent inability as suggested by Kuchlein $(1965,1966,1967)$.

Trend $\mathrm{C}$ is represented by vines 3 and 15 (fig. 7) 3, 7, 11, and 15 (fig. 8) and 3 and 7 (fig. 9). Trend D is represented by vine 19, (fig. 6), vine 19 (fig. 7), vine 19 (fig. 8 ), and vines 19 and 15 (fig. 9).

Trend D of figure 3 represents the extreme conditions when $M$. occidentalis was conspicuously absent during most of the summer. Thus, the Pacific mite was able to increase under favorable nutritional and weather conditions of the vineyard in mid-summer. Undoubtedly, the crash in August was due to density-dependent leaf injury caused by the population itself, for predators were relatively scarce. Some populations in the same test that had not reached such high levels persisted for 


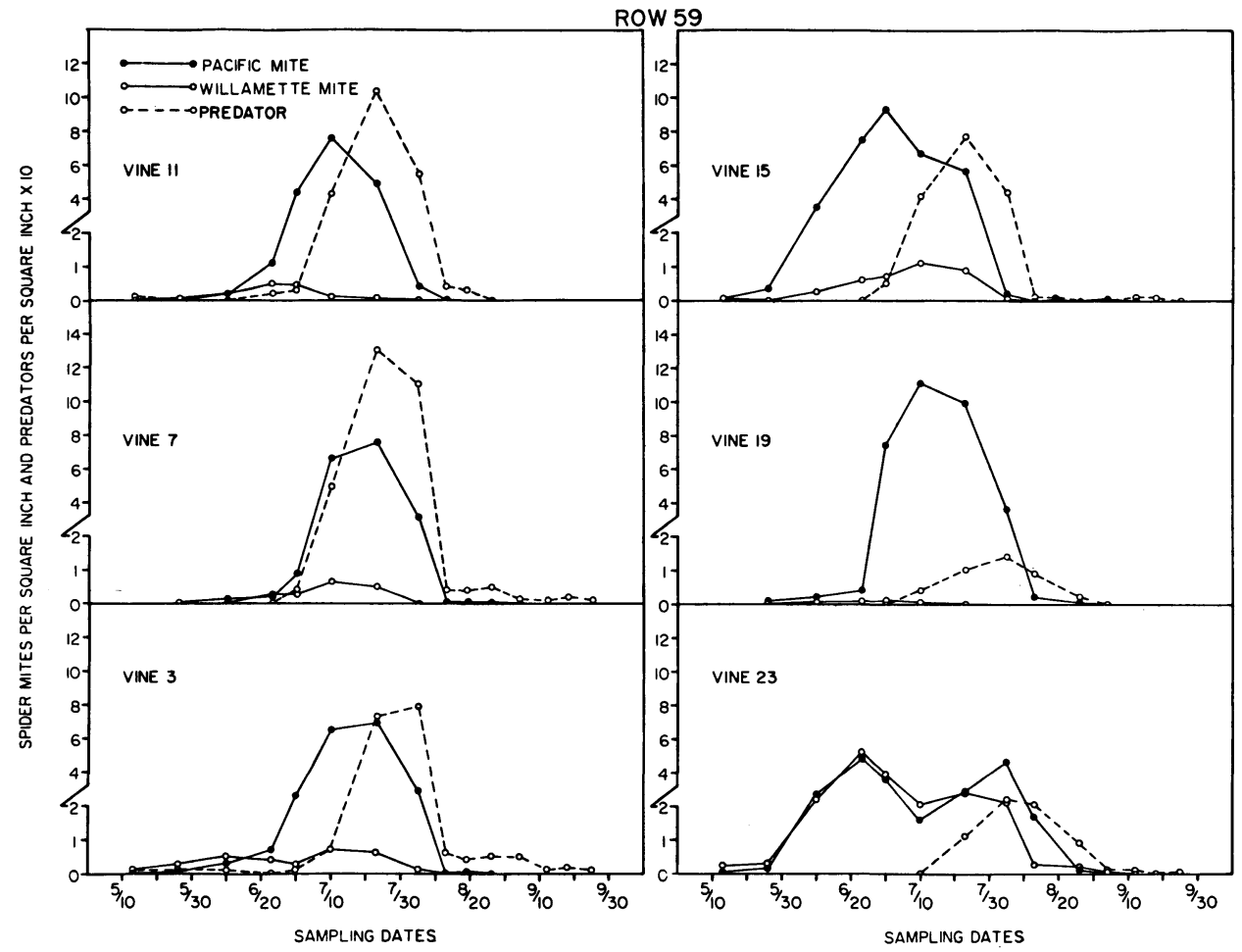

Fig. 6. Population counts on each sample vine. Row 59 was treated in 1965 with endosulfan and dicofol but was not treated in 1966. Miguel vineyard, 1966.

three to four weeks longer; thus, density-independent, seasonal curtailment alone was not responsible. It is noteworthy that $\mathrm{C}$ vines also exhibited crashing populations because of vine injury, despite better predation on these vines than on $\mathrm{D}$ vines. The injury-induced crashes on the $\mathrm{C}$ vines occurred because the longer predator-lag periods permitted the Pacific mite to escape. Therefore, it is important to state here that the greatest value of $M$. occidentalis lies in its acting before the Pacific mite can attain its increase potential; and this is accomplished by holding or regulating this prey species at very low densities in early summer, such as appears to be the case illustrated in trend A. Flaherty and Huffaker (part I) showed that this predator is usually quite active prior to significant Pacific mite increases during the summer in untreated vineyards in the Biola area, while it is definitely slow to respond in vineyards with treatment histories.

In general, trend $\mathrm{A}$ vines had peak Pacific mite populations of less than 4 per square inch; those represented by trend $\mathrm{B}$ had Pacific mite populations of less than 10 per square inch; C or D vines had more than 10 per square inch. $\mathrm{C}$ vines averaged about 12.6 Pacific mites per square inch, while $\mathbf{D}$ vines averaged about 14.3 per square inch. D-vine populations probably did not go much higher than $\mathrm{C}$ vine populations because of the vine-injury limitation.

A group of vines in figures 4 to 9 which do not seem to fall into any of the $\mathrm{A}, \mathrm{B}, \mathrm{C}$, or $\mathrm{D}$ trend categories are illustrated in figure 3 as trend $\mathbf{E}$ vines. All these vines have in common fairly low, seasonal, Pacific mite densities. All 


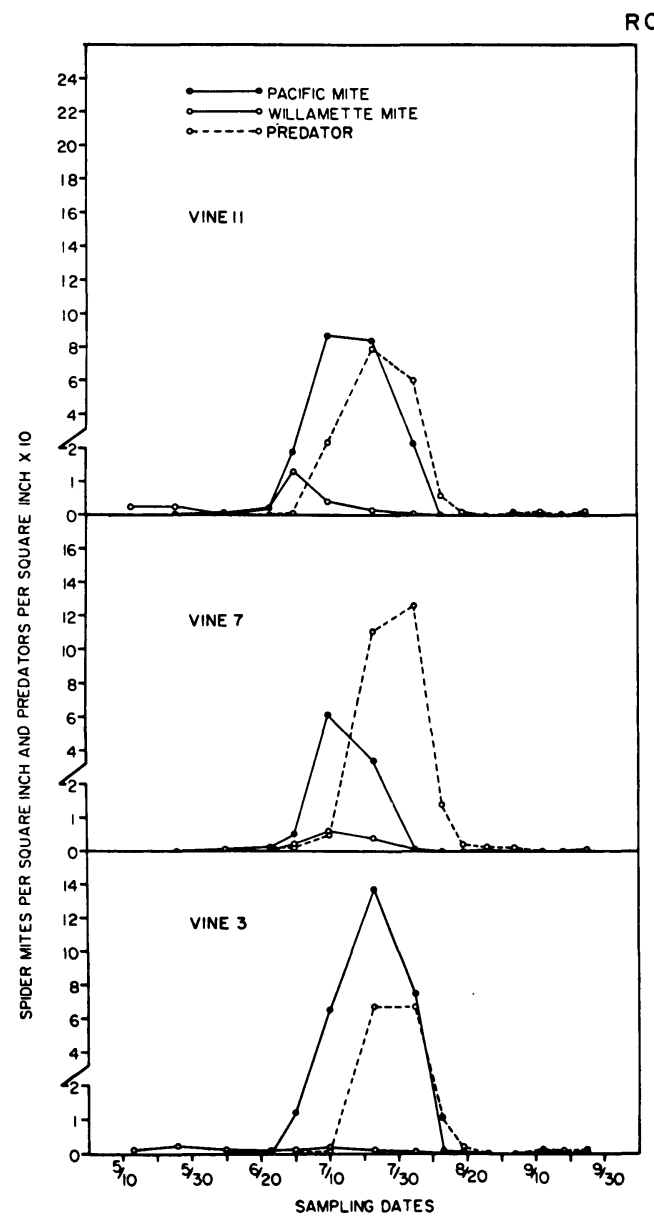

ROW 60

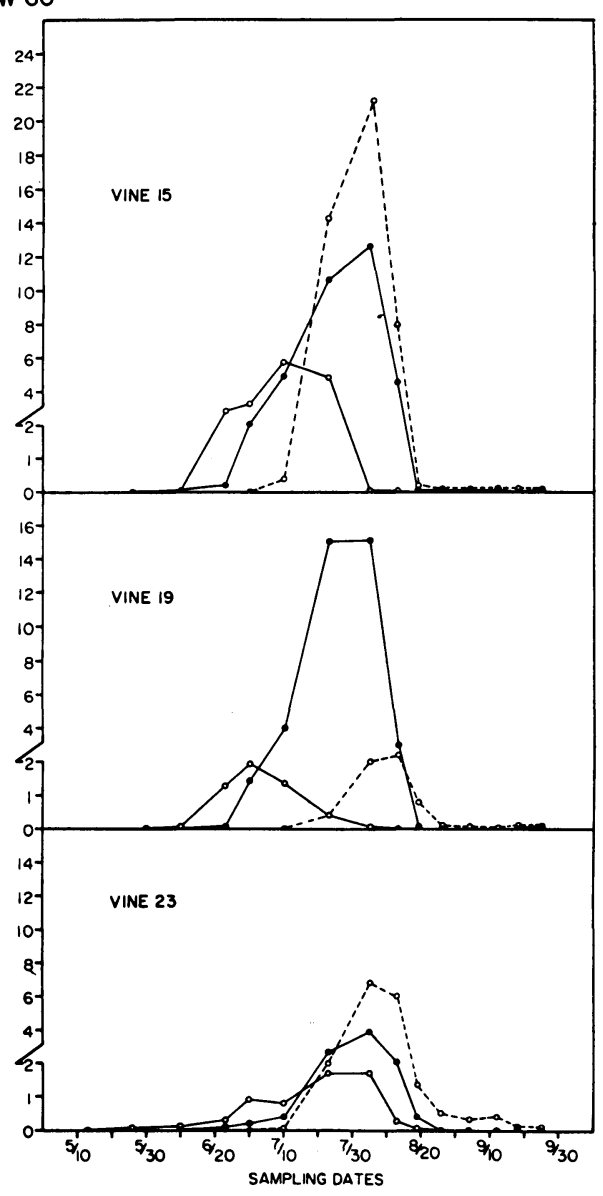

Fig. 7. Population counts on each sample vine. Row 60 was not treated in 1965 or 1966. Miguel vineyard, 1966.

vines numbered 23 in rows 58 to 62 , plus vine 11, row 62 (fig. 9) fall into this group. Why Pacific mite populations were somewhat suppressed or delayed in developing on these vines is not known. It will be recalled that $\mathbf{A}$ vines also had low, seasonal, Pacific mite densities, but the population trends on those vines differed somewhat from those on $\mathbf{E}$ vines. For example, while Pacific mite populations on $\mathbf{A}$ vines were decreasing during the beginning of the mid-summer period because of intense predation, populations of this species on $\mathbf{E}$ vines were, for the most part, increasing-and predators were still lagging in response. Population trends on $\mathrm{E}$ vines are similar to those on B, C, and D vines, except that on $\mathrm{E}$ vines, Pacific mites did not express their potential during the favorable mid-summer period. This suggests abiotic influence.

Thus, individual vine studies not only suggest the importance of predator action, but also the importance of nutritional or some other density-independent action. Also, it should be noted here that predator populations were able to respond to low prey densities on these $\mathrm{E}$ vines, even if belatedly. This delay in predator response on $\mathbf{E}$ vines, in con- 

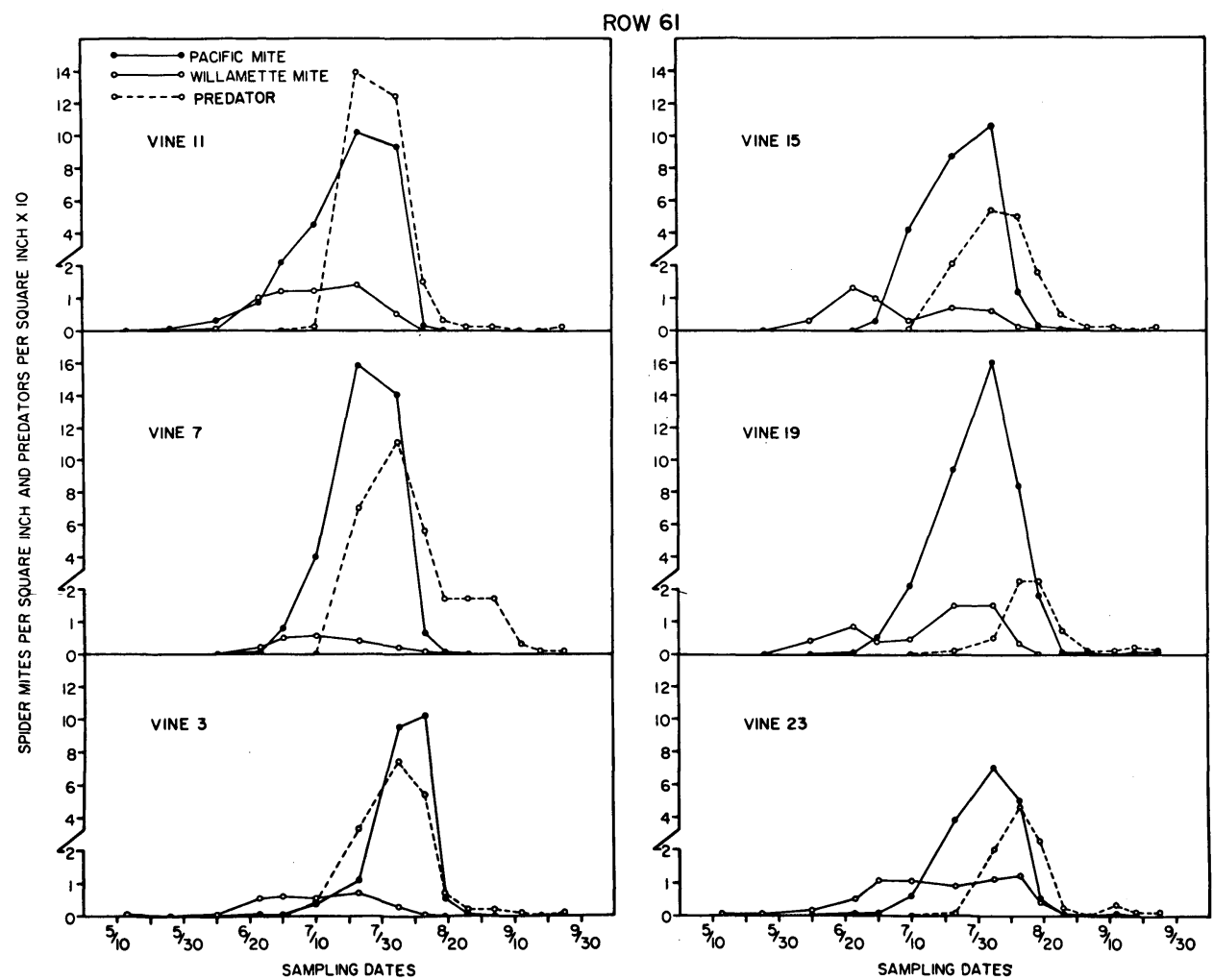

Fig. 8. Population counts on each sample vine. Row 61 was not treated in 1965 or 1966.

Miguel vineyard, 1966.

trast to the earlier response on $\mathrm{A}$ vines, may be attributed to the absence or poor distribution of the predator.

Two other vines-11 and 19, figure 5 -which are not represented in figure 3 , also show unusual population trends. On vine 11 , the high activity of the predator during the early-summer period and the annihilation of Pacific mites during the favorable period of mid-summer probably make the trends on this vine more typical of $A$ vines than the other types. But its very high, early-season Pacific mite population (relative to Willamette mite) precludes this classification. Population trends of vine 19 are similar to those of vine 11 , but unlike vine 11 , predator activity was poor during the early summer on this vine. Fairly high densities of Pacific mites persisted on vine 19 . $A$ combination of vine injury and predation, not unlike that on $\mathrm{C}$ vines, was probably responsible for the sharp decline of Pacific mites in late July on vine 19.

'Trend F, figure 3 , represents a vine where treatment with dicofol during the same season caused a disruption of the normal interactions. The six vines of this type are shown in figure 4 . Their estimated pretreatment populations were different, as were those of the untreated vines. But, in each case, the treatment with dicofol greatly reduced both the Willamette mite and Pacific mite populations and caused severe, almost uniform, destruction of the predator population. For this reason, these six vines presented more uniform population histories than did the various untreated vines. In every case, Pacific mite subsequently increased again to peak levels of three to seven mites per square 

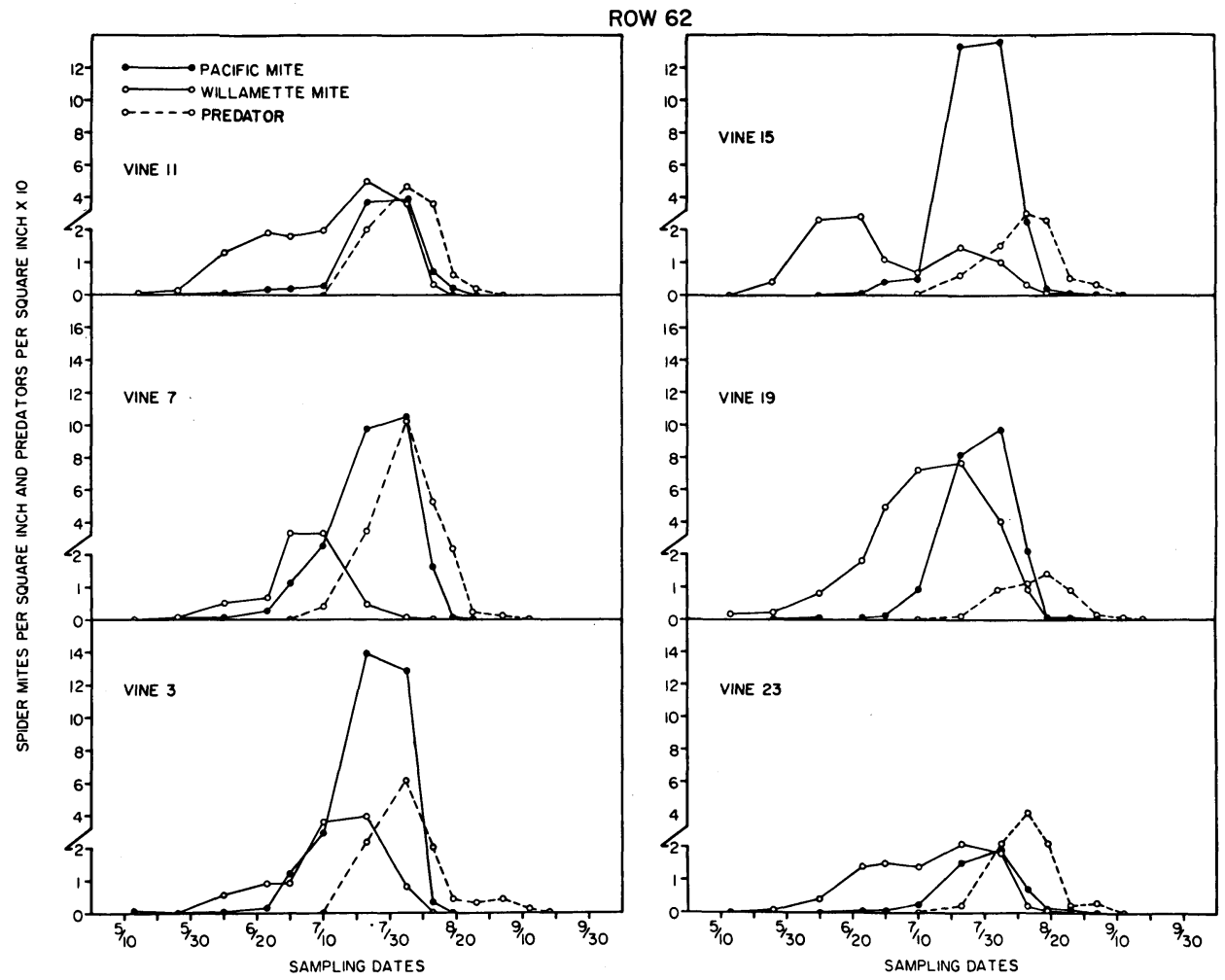

Fig. 9. Population counts on each sample vine. Row 62 was treated in 1965 with endosulfan and dicofol but was not treated in 1966. Miguel vineyard, 1966.

inch. In late August, however, a general decline occurred.

Two facts should be noted: (1) The late August decline of Pacific mite populations on $F$ vines was gradual, not sharp and drastic, as was true on $\mathrm{C}$ and $\mathrm{D}$ vines. Since predation was nil on these vines, seasonal factors and, to a lesser degree, vine injury probably were responsible. (2) Willamette mite, unlike Pacific mite, did not recuperate from the dicofol treatment.

Flaherty and Huffaker (part I) considered that indiscriminate use of chemicals in the Biola area may have led to poor predator and Willamette mite relationships and, consequently, ineffective predation of the more serious $\mathrm{Pa}$ cific mite. Their studies indicated that late-season Willamette mite activity in vineyards is conducive to producing good numbers of overwintering predators, and a continuation of effective pre- dation on Pacific mites the following spring. Vineyards with pesticide histories, in contrast to untreated vineyards, characteristically exhibit very little late-season Willamette mite activity, few predators overwintering under cane bud scales, and ineffective predator populations the following spring. These relations are currently being investigated in greater detail.

We recognize that the data in table 2 and figure 3 only indicate a correlation between degree of dispersion of predators and subsequent degree of control. However, since this greater dispersion of predators is also associated with greater numbers of predators, the data do not directly support the view that predator dispersion, as distinct from numbers of predators, is an important control factor. Thus, vines having more predators also have more leaves carrying predators, and the improved con- 


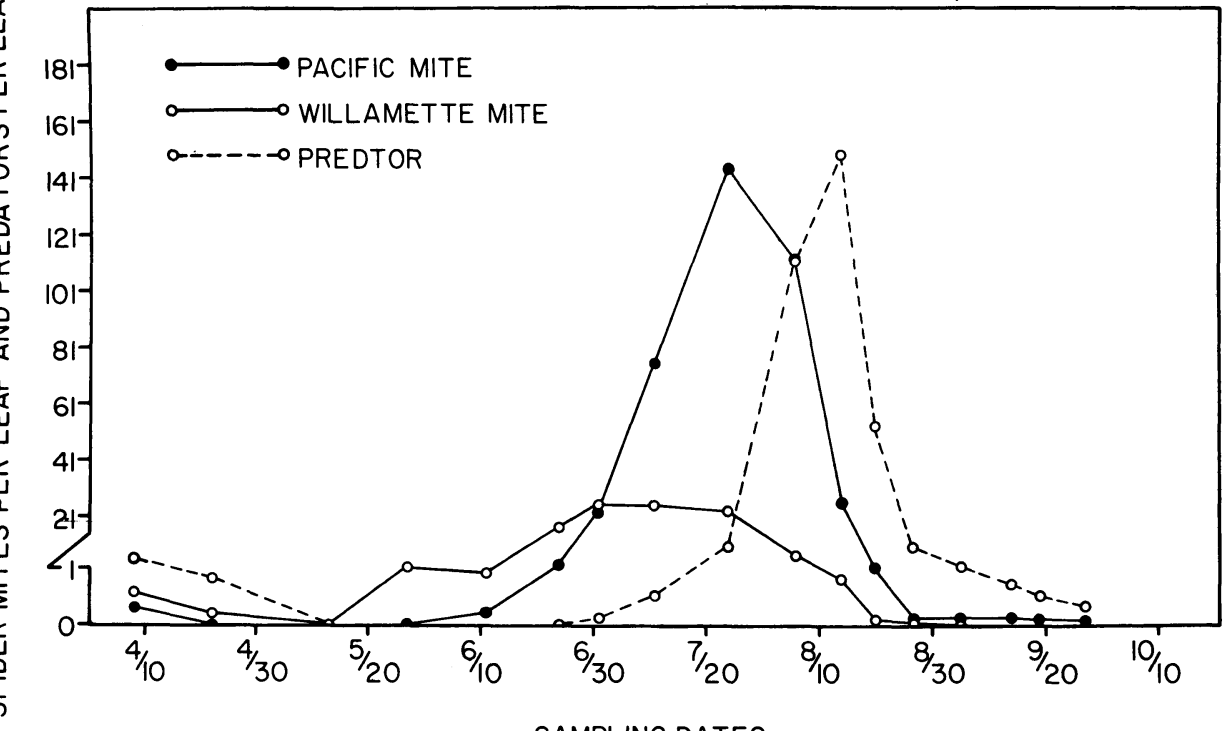

Fig. 10. Population counts for each sampling date lumped from 30 vines in plot; the six treated vines on row 57 were not included.

trol is not clearly related to the one or the other fact. However, it seems logical that less effective control would result later where there is a clumped predator distribution (if not sychronous with a clumped prey population) than where the same number of predators are better dispersed.

To test the importance of dispersion where predator numbers were the same, vine data were arranged into two groups having contrasting predator dispersion but equal predator numbers at a critical date in early summer, June 30. The subsequent prey densities (table 3) actually occurred.

Two groups of eight vines each were selected from 18 vines that were sampled individually on rows 58,59 , and 60 (see fig. 2). In one group of vines, half the total number of predators counted on June 30 on these 18 vines were distributed over all eight vines, so that each of the eight vines had predators on that date. In the second group of eight vines, the remaining half of the predators were distributed over only three vines, that is, in a clumped distribution. Also, for the second group, five vines were then taken randomly from the remaining seven vines of the three rows. These seven vines all lacked predators on the June 30 count. Numbers and dispersion of prey populations on June 30 were also approximately the same for the two groups.

Not all vines in the plot (fig. 2) were included. With only 11 vines having predators on June 30 (all on rows 58, 59 , and 60 ), we had to limit the number of total vines, so that every vine in one group had predators on June 30; while predators were heavily clumped in the other group. Table 3 presents the individual vine data for June 30 and the subsequent population trends from early summer to early fall in the two groups.

To the extent that table 3 may represent vineyard situations, poorly dispersed predator populations are less effective in controlling spider mites than 
TABLE 3

EARLY SUMMER (JUNE 30) PREDATOR AND PREY COUNTS ON TWO GROUPS OF VINES ARRANGED TO HAVE SAME NUMBER OE PREDATORS "DISPERSED" ON ALL EIGHT VINES OF ONE GROUP AND “CLUMPED” ON ONLY THREE OF EIGHT VINES OF THE (OTHER GROUP; ALSO, POPULATION TRENDS OF SAME TWO GROUPS FROM JUNE 30 TO EARLY FALL SHOWING RELATIONSHIP BETWEEN PREDATOR DISPERSION AND SUBSEQUENT PREY CONTROL. MIGUEL VINEYARD. (1966)

June 30 count on nine leaves from each vine* when predator population is:

\begin{tabular}{|c|c|c|c|c|c|c|c|c|c|}
\hline \multicolumn{5}{|c|}{ Dispersed } & \multicolumn{5}{|c|}{ Clumped } \\
\hline \multirow{2}{*}{ Row : vine } & \multicolumn{2}{|c|}{ No. leaves with $\dagger$} & \multicolumn{2}{|c|}{ No. individuals } & \multirow{2}{*}{ Row: vine } & \multicolumn{2}{|c|}{ No. leaves with } & \multicolumn{2}{|c|}{ No. individuals } \\
\hline & Prey & Predators & Prey & Predators & & Prey & Predators & Prey & Predators \\
\hline $58: 1 \ldots \ldots \ldots$ & 8 & 3 & 471 & 26 & $58: 3 \ldots \ldots$ & 9 & 3 & 1,417 & 69 \\
\hline $58: 2 \ldots \ldots \ldots$ & 8 & 4 & 454 & 51 & $58: 4 \ldots \ldots$ & 9 & 6 & 510 & 37 \\
\hline $58: 5 \ldots \ldots \ldots$ & 9 & 2 & 1,597 & 12 & $58: 6 \ldots \ldots$ & 7 & 0 & 629 & 0 \\
\hline $59: 1 \ldots \ldots \ldots$ & 6 & 1 & 437 & 1 & $59: 6 \ldots \ldots$ & 7 & 0 & 953 & 0 \\
\hline $59: 2 \ldots \ldots \ldots$ & 6 & 2 & 164 & 6 & $60: 1 \ldots \ldots$ & 5 & 0 & 229 & 0 \\
\hline $59: 3 \ldots \ldots$ & 8 & 2 & 873 & 5 & $60: 2 \ldots \ldots$ & 4 & 1 & 107 & 2 \\
\hline $59: 4 \ldots \ldots$ & 8 & 4 & 1,379 & 7 & $60: 4 \ldots \ldots$ & 7 & 0 & 944 & 0 \\
\hline $60: 3 \ldots \ldots$ & 7 & 1 & 409 & 1 & $60: 5 \ldots \ldots$ & 5 & 0 & 499 & 0 \\
\hline Total... & 60 & 19 & 5,784 & 109 & Total.... & 53 & 10 & 5,288 & 108 \\
\hline
\end{tabular}

\begin{tabular}{|c|c|c|c|c|}
\hline \multirow{3}{*}{ Date of count } & \multicolumn{4}{|c|}{ Population trends to end of summer when predators are: } \\
\hline & \multicolumn{2}{|c|}{ Dispersed } & \multicolumn{2}{|c|}{ Clumped } \\
\hline & No. prey & No. predators & No. prey & No. predators \\
\hline $6 / 30 \ldots \ldots \ldots \ldots \ldots$ & 5,784 & 109 & 5,288 & 108 \\
\hline $7 / 10 \ldots \ldots \ldots \ldots \ldots$ & 6,858 & 388 & 5,953 & 167 \\
\hline $7 / 23 \ldots \ldots \ldots \ldots$ & 6,354 & 852 & 9,259 & 659 \\
\hline $8 / 5 \ldots \ldots \ldots \ldots \ldots \ldots$ & 1,710 & 584 & 7,489 & 754 \\
\hline $8 / 13 \ldots \ldots \ldots \ldots \ldots$ & 7 & 33 & 1,504 & 217 \\
\hline $8 / 19 \ldots \ldots \ldots \ldots \ldots$ & 6 & 28 & 306 & 64 \\
\hline $8 / 26 \ldots \ldots \ldots \ldots \ldots$ & 8 & 37 & 160 & 62 \\
\hline $9 / 4 \ldots \ldots \ldots \ldots \ldots \ldots$ & 11 & 28 & 20 & 19 \\
\hline Total............. & 20,738 & 2,059 & 29,979 & 2,050 \\
\hline
\end{tabular}

* Figs. 5 to 7 illustrate the population trends on the individual vines in this table.

$\dagger$ Number of leaves in nine with prey and predators.

the same predator numbers more widely dispersed. Thus, 29,979 prey were counted on the vines with highlyclumped predator populations, and 20,738 prey were counted on vines with dispersed predator populations-a difference of nearly 50 per cent.

Table 3 indicates that an initially dispersed predator population is likely to increase in numbers more quickly than an initially clumped predator population. It is present at more foci of prey and finds more new foci. Therefore, in certain phases of predator-prey interaction, the number of predators and their effectiveness may actually be a subsequent function of dispersion. Dispersion is also, of course, a subsequent function of numbers, simply because there are more predators to move about. But in the latter case, spider mite. populations may increase to vinedamaging numbers before predators are able to achieve area-wide sufficiency. 
Flaherty (1969) and Flaherty and Huffaker (part I) present further data showing the importance of early preda- tor increase and dispersion for effective control of spider mites.

\section{SUMMARY AND CONCLUSIONS}

The present investigation indicates that attributes of the prey population, not of the individual as such, dictate the efficiency with which Metaseiulus occidentalis (Nesbitt) responds to and controls a given spider mite species population. Studies on Thompson Seedless grapevines showed that the aggregating Pacific mite (Tetranychus pacificus McGregor) is more likely to encourage greater and more effective numbers of predators than the more widely dispersed Willamette mite (Eotetranychus willamettei Ewing). Also, webbing, which Pacific mite aggregations produce more abundantly than do Willamette mites, may be attractive to predators.

The study also showed that under vineyard conditions, $M$. occidentalis has the ability to respond numerically to low or high prey densities. Moreover, the efficiency with which this predator controls its prey is a function of its dispersion as well as its numbers. Using individual vines as study units, it was illustrated that the length of lag in predator response is mainly a function of the predator's absence or poor distribution relative to its prey.

In the absence of effective predation in otherwise favorable vineyard conditions, Pacific mites are regulated primarily by vine damage inflicted by their own increasing populations. This form of control is, of course, disastrous for the vineyardist. On the other hand, some vines exhibit very low Pacific mite populations, despite a poor response in the predator populations. Such low densities are interpreted as being due to unfavorable edaphic or vine nutri- tional factors. Thus, individual vine studies may delineate not only the importance of effective predation (delayed density-dependent action), but the importance of abiotic factors (density-independent actions), as well. Lumping of sampling data from large groups of vines precludes the separation of these two equally important facets of natural control.

Finally, the study indicates that chemical treatments may disrupt predator and prey distributional patterns in two ways: First, while predators are annihilated by the treatments, small numbers of surviving Pacific mites may subsequently increase again to heavily damaging numbers. Thus, these vines may exhibit poor predator-prey relations at the end of the season. That is, in contrast to the successful overwintering of Pacific mites, few predators may overwinter on these vines. Secondly, prey annihilation by treatments may preclude the availability of food for the predator and thus short-circuit its continuous activity. Willammette mite populations, unlike Pacific mite populations, did not recuperate from a dicofol treatment. Other studies in the Biola area (Flaherty and Huffaker, part I) show that late-season, Willamette mite activity often insures that good numbers of predators will enter hibernation. Pacific mites decline too early in the season in this area to serve suitably as lateseason prey. Hence, if Willamette mites are annihilated by treatments or any other action-for example, excessive predation-too few predators will be able to prepare for the necessary hibernation. 


\section{LITERATURE CITED}

ANDERson, N. H., and C. V. G. MorgaN

1958. The role of Typhlodromus spp. in British Columbia apple orchards. Proc. 10th Intern. Congr. Ent., Montreal, 1956, 4: 659-65.

Chant, D. A.

1959. Phytoseiid mites (Acarina: Phytoseiidae). Part I. Bionomics of seven species in southeastern England. Part II. A taxonomic review of the family Phytoseiidae, with descriptions of 38 new species. Can. Ent. 91, Suppl. 12: 166 pp.

1961. The effect of prey density on prey consumption and oviposition in adults of Typhlodromus (T.) occidentalis (Acarina: Phytoseiidae) in the laboratory. Can. Jour. Zool. 39: 311-15.

Chant, D. A., and C. A. Fleschner

1960. Some observations on the ecology of phytoseiid mites in California. Entomophaga 5: 131-39.

Collyer, E.

1964a. A summary of experiments to demonstrate the role of Typhlodromus pyri Scheut. in the control of Panonychus ulmi (Koch) in England. Acarologia 9: 363-71.

1964b. The effect of alternate food supply on the relationship between two Typhlodromus species and Panonychus ulmi (Koch). Ent. Exptl. Appl. 7: 120-24.

Dosse, G.

1960. Über den Einfluss der Raubmilbe Typhlodromus tiliae Oud. auf die Obstbaumspinnmilbe Metatetranychus ,ulmi Koch. (Acari). Pflanzenschutz Ber. 24: 113-37.

Flaherty, D. L.

1969. Vineyard trophic complexity and Willamette mite, Eotetranychus willamettei Ewing (Acarina: Tetranychidae) densities. Ecology 50 : 911-16.

HUFFAKER, C. B.

1958. Experimental studies on predation: dispersion factors and predator-prey oscillations. Hilgardia 27(14) : 343-83.

HUFFaker, C. B., and D. L. Flaherty

1966. Potential of biological control of two-spotted spider mites on strawberries in California. Jour. Econ. Ent. 59 : 786-92.

HUFFAKER, C. B., and C. E. KENNETT

1956. Experimental studies on predation: predation and cyclamen mite populations on strawberries in California. Hilgardia 26(4): 191-222.

Huffaker, C. B., AND C. H. SpITzer, JR.

1950. Some factors affecting red mite populations on pears in California. Jour. Econ. Ent. 43: 819-31.

Huffaker, C. B., K. P. Shea, AND S. G. Herman

1963. Experimental studies on predation: complex dispersion and levels of food in an acarine predatory-prey interaction. Hilgardia 34(9): 305-30.

HUfFAKER, C. B., vAN DE VRIE, AND J. A. MCMURTRY

1969. The ecology of tetranychid mites and their natural control. Ann. Rev. Ent. 14: 125-74.

KROPCZÝ́sKA, D., and M. VAN DE VRIE

1965. The distribution of phytophagous and predacious mites on apple leaves. Boll. Zool. Agr. Bachic. Milano. Ser. II(7): 107-12.

\section{KUCHLEIN, J. H.}

1965. A reconsideration of the role of predacious mites in the control of European red spider mite in orchards. Boll. Zool. Agr. Bachic. Milano. Ser. $\Pi(7): 113-18$.

1966. Mutual interference among the predacious mites Typhlodromus longipilus Nesbitt (Acari, Phytoseiidae). I. Effects of predator density on oviposition rate and migration tendency. Meded. Rijksfac. Landb.-wetensch. Gent 31: 740-46.

1967. The density-related action of aphidophagous insects. Vest. esl. Spol. Zool. (Acta. Soc. Zool. Bohemoslov.) 31: 162-69.

LAING, J. E., AND C. B. HuFfakeR

1969. Comparative studies of predation by Phytoseiulus persimilis Athias-Henriot and Metaseiulus occidentalis (Nesbitt) (Acarina: Phytoseiidae) on populations of Tetranychus urticae Koch (Acarina: Tetranychidae). Res. Popul. Ecol XI: 105-26. 
SмITH, L. M.

1939. Control of Pacific mites on grapes. Univ. of Calif. College of Agr. Exp. Sta. Prog. Rpt. 615: 14-16.

1950. Mite populations on grapes. Effects of sulfur dust treatments on predatory mites and red spider mites. Calif. Agr. 4(3): 13-14.

Smith, L. M., AND E. M. STAFFoRd

1955. Grapes pests in California. Calif. Agric. Exp. Sta. Ext. Ser. Cir. 445: 61 pp.

VAN DE VRIE, M., and D. KROPCZYŃsKa

1965. The influence of predatory mites on the population development of Panonychus ulmi (Koch) on apple. Boll. Zool. Agr. Bachic. Ser. II(7) : 119-30.

WATERS, N.

1955. Biological and ecological studies of Typhlodromus mites as predators of six-spotted spider mite. Ph.D. thesis, Univ. Calif. Berkeley.

To simplify the information, it is sometimes necessary to use trade names of products or equipment. No endorsement of named products is intended nor is criticism implied of similar products not mentioned. 


\section{Influence of Dispersion Patterns of Metaseiulus occidentalis}

This study revealed that prey population attributes, not individual attributes, dictate the efficiency with which Metaseiulus occidentalis (Nesbitt) (Acarina: Phytoseiidae) responds to and controls populations of given spider mite species (Eotetranychus willamettei Ewing and Tetranychus pacificus McGregor) on grapevines.

The study also showed that under vineyard conditions, $M$. occidentalis has the ability to respond numerically to low or high prey densities. Using individual vines as study units, the length of the lag in predator response to low or high prey densities was shown to be mainly a function of absence or poor distribution of the predator relative to its prey.

Individual vine studies may delineate not only the importance of predation (delayed density-dependent action) but the importance of abiotic factors (density-independent actions), as well. Lumping of sampling data from large groups of vines precludes the appraisal and separation of these two equally important facets of natural control.

Finally, the studies indicate that chemical treatments may disrupt predator and prey distributional patterns, either directly by annihilating the predators or indirectly by annihilating their prey, or a combination of the two. 
The journal HILGARDIA is published at irregular intervals, in volumes of about 650 to 700 pages. The number of issues per volume varies.

Single copies of any issue may be obtained free, as long as the supply lasts; please request by volume and issue number from:

\author{
Agricultural Publications \\ University Hall \\ University of California \\ Berkeley, California $\mathbf{9 4 7 2 0}$
}

The limit to nonresidents of California is 10 separate titles. The limit to California residents is $\mathbf{2 0}$ separate titles.

The journal will be sent regularly to libraries, schools, or institutions in one of the following ways:

1. In exchange for similar published material on research.

2. As a gift to qualified repository libraries only.

3. On a subscription basis $-\$ 7.50$ a year paid in advance. All subscriptions will be started with the first number issued during a calendar year. Subscribers starting during any given year will be sent back numbers to the first of that year and will be billed for the ensuing year the following January. Make checks or money orders payable to The Regents of The University of California; send payment with order to Agricultural Publications at above address. 